www.nature.com/ejcn

\title{
EDITORIAL Bioelectrical Impedance Analysis
}

European Journal of Clinical Nutrition (2013) 67, S1; doi:10.1038/ ejcn.2012.148

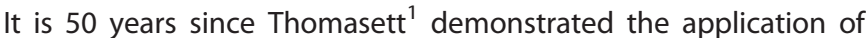
the measurement of the impedance of the human body to the estimation of total body water. The use of the bioelectrical impedance technique for the analysis of body composition, however, largely languished for a further 20 years until Nyoboer used impedance techniques to estimate the fat and fat-free mass (FFM) of the human body. ${ }^{2} \mathrm{~A}$ few years later saw the publication of the seminal paper by Lukaski et al., ${ }^{3}$ in which the method was validated against reference methods of deuterium dilution and total body potassium measurement. This marked the start of a quarter of century of intensive research and development in the field, expansion of the technology into other areas of biomedical research and popularisation of the technology fostered by the development of inexpensive impedance-based body composition analysers for home use.

During the last 20 years, the first position paper on bioelectrical impedance analysis (BIA) was published in 1996, ${ }^{4}$ followed by an update in 1999..$^{5}$ There has been a more recent 2004 review by an ESPEN working group. ${ }^{6,7}$ These highly cited papers covered a very broad spectrum of applications and methodological details. More recent advances in BIA technology, as well as the use of BIA raw data and/or derivatives of raw data such as phase angle and bioelectrical impedance vector analysis (BIVA), gave rise to detailed and sophisticated data analyses and targeted applications in clinical practice. On the basis of theoretical principles, BIA is most appropriately reserved for the assessment of body hydration. This includes total body water, as well as intracellular and extracellular water. In longitudinal assessments, overhydration and dehydration, as well as the effect of respective treatments, can be followed by BIVA. Assuming a fixed hydration, FFM and body cell mass can be calculated from BIA data. These two body components are measures of functional body mass, which gives rise to the second application of BIA focussing on malnutrition and rehabilitation. As BIA gives an indirect estimate of fat mass (which is calculated from the difference between body weight and FFM), the third application is on energy stores and thus lies at the centre of clinical nutrition. In addition to hydration, functional body mass and energy stores, BIA may also serve as a monitor of disease load; a low-phase angle is associated with poor prognosis. Thus, as a fourth application, BIA data reflect the severity of disease in acutely and chronically ill patients. Altogether, BIA (such as ECG for interpretation of cardiac function) is a central tool in the clinical examination of patients addressing hydration, functional body mass, energy stores and prognosis.
This supplement brings together contributions from many leading researchers in the bioimpedance field. The papers range from reviews covering the history and development of BIA through its use in different populations and settings to contemporary and novel applications including new instrumentation and approaches to data analysis. The papers in this supplement are testament to extensive research that continues in the bioimpedance field and foreshadow that the next quarter of a century will be as productive as the past.

\section{CONFLICT OF INTEREST}

Ward has consulted to ImpediMed Ltd. Müller has consulted to seca Gmbh \& Co. KG; both consultations had no involvement in the conception and execution of this study or in the preparation of the manuscript.

\section{ACKNOWLEDGEMENTS}

Publication of this supplement was supported by a grant from seca Gmbh \& Co. KG, Hamburg, Germany.

\section{LC Ward ${ }^{1}$ and MJ Müller ${ }^{2}$ \\ ${ }^{1}$ School of Chemistry and Molecular Biosciences, The University of Queensland, Brisbane, Queensland, Australia and ${ }^{2}$ Institut für Humanernährung und Lebensmittelkunde, Christian-Albrechts-Universität zu Liel, Kiel, Germany}

E-mail: I.ward@uq.edu.au

\section{REFERENCES}

1 Thomasset A. Bioelectrical properties of tissue impedance. Lyon Medical 1962; 207: 107-118

2 Nyboer J. Percent body fat by four terminal bio-electrical impedance and body density in college freshman. Proceedings of the Vth International Conference on Electrical Bio-Impedance. Tokyo, August 1981.

3 Lukaski HC, Johnson PE, Bolonchuk WW, Lykken Gl. Assessment of fat-free mass using bioelectrical impedance measurements of the human body. Am J Clin Nutr 1985; 41: 810-817.

4 National Institutes of Health Technology Assessment Conference Statement. Bioelectrical impedance analysis in body composition measurement. Am J Clin Nutr 1996; 64: 524S-532S.

5 Ellis KJ, Bell SJ, Chertow GM, Chumlea WC, Knox TA, Kotler DP et al. Bioelectrical impedance methods in clinical research: a follow-up to the NIH Technology Assessment Conference. Nutrition 1996; 15: 874-880.

6 Kyle UG, Bosaeus I, De Lorenzo AD, Deurenberg P, Elia M, Gómez JM et al. (ESPEN working group). Bioelectrical impedance analysis-part I: review of principles and methods. Clin Nutr 2004; 23: 1226-1243.

7 Kyle UG, Bosaeus I, De Lorenzo AD, Deurenberg P, Elia M, Manuel Gómez J et al. (ESPEN working group). Bioelectrical impedance analysis-part II: utilization in clinical practice. Clin Nutr 2004; 23: 1430-1453. 